\title{
A Study to Establish Correlation Between Rebound Value and Compressive Strength of Concrete Using Materials Available Locally in Nagpur
}

\author{
Aman Raj, Pramod Deshmukh, and Pradeepa.S
}

\begin{abstract}
This study has been taken to investigate the exact rebound-strength relationship of different grades of concrete, as the curves generated for traditional hammers are outdated. Using the material available in the Nagpur region, cube specimens were cast and tested as per IS:516-1959. Several sets were cast with varying cement contents, decided by mix design, to give a strength range of 10 to $50 \mathrm{Mpa}$. However, for this study, the Target Mean Strength Standard Deviation factor is not considered. We tested these sets for compressive strengths; each specimen was checked for rebound value for compressive Strength, and each specimen was checked for rebound value on four faces. Thus, for each specimen, data for rebound value and Compressive Strength is available. Using this data, a curve for Compressive Strength and rebound value was plotted. The curve generated indicated that the strengths obtained for the same rebound value are higher than that using the traditional curve. There is an increase of about $47 \%$ up to a strength of $21 \mathrm{Mpa}$. From 21 to $38 \mathrm{Mpa}$, this increase is almost constant at about $30 \%$. From this point forward, the rate of increased Strength reduces by $25 \%$ and $14 \%$ at $40 \mathrm{Mpa}$ and $45 \mathrm{Mpa}$, respectively.
\end{abstract}

Index Terms - Compressive Strength, Rebound Value Ernst Schmidt, Rebound Hammer Test

\section{INTRODUCTION}

During construction, to ensure the Strength of concrete that is being used, it is a routine practice to cast concrete cubes and test for compressive strength. However, it is found that despite adequate quality assurance; variance in concrete Strength from batch to batch is inevitable. In addition, the number of test specimens is usually so small that they can be considered random tests. Thus, there can be uncertainty about the exact Strength of concrete in the structure[1].

Sometimes, particularly in case of failures, rebound hammer tests are employed. However, the depth of influence of hammer impact is so small that actually, it represents properties of concrete for outer 30-50 $\mathrm{mm}$. Hence, at times it is difficult to relate rebound value and the Strength of

Manuscript revised October 19, 2021 and published on November 10, 2021

Aman Raj, Under Graduate Student, Civil Engineering, Visvesvaraya Institute of Technology, Bengaluru, India.

Pramod Deshmukh, Director Technical Highway Division, Geotech Services Pvt. Ltd., Nagpur, India. concrete as a whole. Also, the strength curves generated for rebound hammers are some fifty years ago- and are being applied universally. It is possible, that there can be different curves for different ingredients used in concrete - as the overall property of concrete is the combined representation of all the materials.

The present study is intended to establish a relation between Schmidt Rebound Hammer Number and the compressive strength of concrete produced using the material utilized around Nagpur.

In the Nagpur region, Basalt rock is available - and coarse aggregates are manufactured by crushing this parent rock Fine aggregates come from two major sources: River Wainganga and River Kanhan. These two rivers contain Quartz sand-which is a weathered product of Feldspar due to their origin from Quartz and Feldspar-rich Madhya Pradesh. These two materials share $70-80 \%$ of the volume of concrete. Hence, the properties of these two materials have a substantial effect on concrete parameters. For the same mix proportion, aggregates from a weaker parent rock, porous sandstone for example, when used, concrete exhibits lower strengths as compared to that when a relatively stronger aggregate, say Limestone, is used.

So, the basic properties of aggregates always affect the properties of concrete. The modulus of elasticity (of concrete) is primarily influenced by the elastic properties of the aggregate and to a lesser by the conditions of curing and age of concrete, the mix proportions, and the type of cement [2]. The same code relates to elasticity and compressive Strength as

$$
E=5000 \sqrt{F_{c k}}
$$

Similarly, flexural and tensile strengths are also related to compressive strengths, Thus, different properties of concrete are related to uniform parameter compressive Strength and hence, determination of true compressive Strength in-situ becomes essential.

In situ Strength can be assessed using the Schmidt rebound hammer. Different types of hammers are available and for each hammer, a correlation curve between rebound value $\mathrm{R}$ and the compressive strength is provided. The curves, however, were developed when the use of Ordinary Portland

Pradeepa.S, Assistant Professor, Civil Engineering, Sir M Visvesvaraya Institute of Technology, Bengaluru, India 
Cements (OPC) was predominated. These may not be apt under material qualities.

The materials chosen for the study are -

\section{A. Portland Pozzolana Cement}

This cement is being used in most of the projects except for a few government-funded projects. M15, M20, M25, M30, M35, and M40 grade of cement was procured.

\section{B. Coarse Aggregate}

In Nagpur, coarse aggregates are crushed stone. After testing, $20 \mathrm{~mm}$ aggregates were found to be oversized while $10 \mathrm{~mm}$ aggregates were flakey.

\section{Natural Sand}

The sand conformed to grading zone 2 of IS:383-1963 [3].

\section{D.Admixture}

Conplast SP 430 G8 of Fosroc Chemicals was used.

\section{Plan}

\section{A. Ensuring Uniformity of Material}

In this phase, initial testing on the material is carried out. Repeat tests are made to ensure that the material is homogenous. If required, the material is remixed or blended with other additional materials to maintain uniformity.

\section{B. Finalizing Concrete Mix Design}

Once, the quality and uniformity of ingredients were ensured, mix design was taken up. The initial theoretical design was worked out as per IS:10262-2009[4]. Mixes were prepared using the finalized material and were checked if any correction was necessary. Once necessary corrections were made, trials were taken by varying cement contents. Strengths were checked at 28 days to freeze the cement content for required Strength.

\section{Specimen Casting and Testing}

After the finalization of concrete mix designs, a set of 12 cubes were cast per grade for each curing period of 7 days and 28 days. Density as determined during mix design was maintained as standard density.

\section{D.Data Analysis}

Once the results are available, trend analysis was conducted using software such as Microsoft Excel regression or CurveExpert curve fit. During curve fitting, parameters such as residuals, standard error, correlation coefficient, etc. are also determined. Attempts were made to get simple fits such as quadratic for easy interpretation of strengths. Also, when the correlation coefficient is less than 0.98 (which approaches 1.0 for the perfect fit), range i.e., upper and lower bound limits for application of curve are defined.

\section{Concrete Mix Design}

For the study, the concrete mixes to be used for different strengths were designed. Standard Deviation is a parameter that is used when mixes are to be designed in the laboratory and is to be used at the site. In such cases, a margin for Strength is necessary for laboratory to site conditions.
In this case, since the specimens were cast under laboratory conditions, this factor of standard deviation has been neglected.

Here, the design of the highest grade M45 concrete has been shown.

\section{A. Finalized Mix for Grade M45 Concrete}

The process of finalization of the mix design of M45 concrete has been shown below-

\section{1) Design Stipulation}

The following design stipulations are considered based on the casting conditions and requirements of IS: 456-2000 [2]. TABLE I: DESIGN STIPULATION FOR M45 CONCRETE

\begin{tabular}{ll}
\hline \hline Properties & Stipulations \\
\hline Type of Concrete & Reinforced Concrete \\
Degree of Exposure & Moderate \\
Degree of Quality Control & Good \\
Degree of Workability & $50-75 \mathrm{~mm}$ Slump \\
Maximum Size of Aggregate & $20 \mathrm{~mm}($ Oversized $)$ \\
Maximum Water Cement ratio & 0.50 \\
Minimum Cement Content & $300 \mathrm{~kg} / \mathrm{m}^{3}$ \\
\hline \hline
\end{tabular}

2) Target Mean Strength (ft)

The target mean strength is given as:

Here,

$$
f_{t}=f_{c k}+K . S
$$

$f_{c k}=$ Characteristic Strength Required

$\mathrm{K}=\mathrm{A}$ statistical value based on the accepted proportion of lower test results and number of tests: 1.65 for $5 \%$ of test results below $f_{c k}$.

$\mathrm{S}=$ Standard Deviation taken as 5.0 Mpa

In this case, the standard deviation is neglected because specimens are processed and tested under laboratory conditions, and the margin for site use is not applicable. Hence, target means Strength is considered as grade designation i.e., $45 \mathrm{Mpa}$.

\section{3) Trial 1}

The initial mix worked out as per IS:10262-2009 [4] is given under -

\begin{tabular}{ll}
\multicolumn{2}{c}{ TABLE II: TRIAL 1 RESULT } \\
\hline \hline Properties & Trial 1 \\
\hline Mix Proportion & $1: 1.38: 2.70$ \\
Water Cement Ratio & 0.38 \\
Cement Content & $452 \mathrm{~kg} / \mathrm{m}^{3}$ \\
Admixture & $1.0 \%$ \\
Initial Slump Observed & $125 \mathrm{~mm}$ \\
Actual Density & $2472 \mathrm{~kg} / \mathrm{m}^{3}$ \\
\hline \hline
\end{tabular}

The following observations were made -

a) The workability achieved is much higher, as, against a requirement of 50-75 $\mathrm{mm}$, the actual slump achieved was $125 \mathrm{~mm}$. As this much workability was not required, the water-cement ratio was reduced to 0.35 . Hence, a correction of -0.03 is necessary for the watercement ratio.

b) Sand content in the mix calculated as per [4] was $33.7 \%$. At this sand content, the mix indicated slight 
segregation. Hence, to produce a cohesive mix, sand content was increased to $35 \%$.

c) Since $20 \mathrm{~mm}$ aggregates are oversized, instead of grading the aggregates to meet IS:383-1970 [3] all-ingrading requirements, aggregates were proportioned by emphasizing more on cohesiveness and workability of the mix rather than grading. This is because the practice of maintaining the cohesiveness of concrete mix is being followed on-site, and the basic object of the proposed study is to establish a correlation between the Strength of as-usedon-site concrete and not a standard one.

Different proportions of ingredients were tried by varying the proportions -to get a cohesive and workable mix. The aggregates proportion was finalized as 60: 40 (20: 10) with $35 \%$ sand content.

\section{4) Trial 2}

The trial was conducted with necessary corrections in the mix, but with a cement rounded to $450 \mathrm{~kg} / \mathrm{m}^{3}$. The details of the mix are given below -

\begin{tabular}{ll}
\hline & TABLE III: TRIAL 2 RESULT \\
\hline \hline Properties & Trial 2 \\
\hline Mix Proportion & $1: 1.44: 2.68$ \\
Water Cement Ratio & 0.35 \\
Cement Content & $450 \mathrm{~kg} / \mathrm{m}^{3}$ \\
Admixture & $1.0 \%$ \\
Initial Slump Observed & $75 \mathrm{~mm}$ \\
7 Days Strength & $32.6 \mathrm{Mpa}$ \\
28 Days Strength (Accelerated) & $46.9 \mathrm{Mpa}$ \\
\hline
\end{tabular}

After trial 2, the following observations were made -

a) The mix prepared with $35 \%$ sand content showed good workability.

b) The strength achieved is satisfactory for M45

\section{5) Trial $3 \& 4$}

Two additional trials with $435 \mathrm{~kg} / \mathrm{m}^{3}$ and $465 \mathrm{~kg} / \mathrm{m}^{3}$ were also tried. This is because, if the previous mix indicated higher Strength, then by reducing the cement content, the mix can be optimized. On the other hand, if trial 2 showed lower Strength, then cement content was to be increased, so, these two trials were done simultaneously to avoid the delay in design, had the previous mix indicated inapt Strength.

\begin{tabular}{lll}
\hline \multicolumn{2}{c}{ TABLE IV : TRIAL 3 AND 4 RESULTS } \\
\hline \hline Properties & Trial 3 & Trial 4 \\
Mix Proportion & $1: 1.51: 2.80$ & $1: 1.38: 2.58$ \\
$\begin{array}{l}\text { Ratio Cement } \\
\text { Cement Content }\end{array}$ & 0.38 & 0.32 \\
Admixture & $1.0 \%$ & $465 \mathrm{~kg} / \mathrm{m}^{3}$ \\
Slump Observed & $60 \mathrm{~mm}$ & $1.0 \%$ \\
7 Days Strength & $30.2 \mathrm{Mpa}$ & 70 \\
28 Days Strength & $\begin{array}{l}41.4 \mathrm{Mpa} \\
\text { Strength does not }\end{array}$ & $43.2 \mathrm{Mpa}$ \\
Remarks & $\begin{array}{l}\text { comply with target } \\
\text { Strength }\end{array}$ & Strength is much \\
\hline \hline
\end{tabular}

\section{6) Finalized Mix for M45}

Based on the above test results, the mix used for trial 2 was finalized.

\section{B. Finalized Mix for Different Grades of Concrete}

The finalization of the mix design for M15, M20, M25, M30, M30, M35, and M40 was done similarly as shown above for M45. Multiple Trials were done for each grade of concrete before deciding on the Mix design closest to Target Mean Strength. The finalized mix designs are presented below-

TABLE V: FINALIZED MIX FOR M15, M20, AND M25 CONCRETE

\begin{tabular}{|c|c|c|c|}
\hline Properties & M15 & M20 & M25 \\
\hline Mix Proportion & $1: 2.59: 4.81$ & $1: 2.35: 4.36$ & $1: 2.34: 3.97$ \\
\hline Water Cement Ratio & 0.50 & 0.50 & 0.48 \\
\hline Cement Content $\left(\mathrm{kg} / \mathrm{m}^{3}\right)$ & 275 & 300 & 325 \\
\hline Sand Content $\left(\mathrm{kg} / \mathrm{m}^{3}\right)$ & 712 & 705 & 696 \\
\hline $\begin{array}{l}\text { Coarse Aggregates } \\
20 \mathrm{~mm} @ 60 \%\left(\mathrm{~kg} / \mathrm{m}^{3}\right)\end{array}$ & 794 & 785 & 774 \\
\hline $\begin{array}{l}\text { Coarse Aggregates } \\
10 \mathrm{~mm} @ 40 \%\left(\mathrm{~kg} / \mathrm{m}^{3}\right)\end{array}$ & 529 & 523 & 516 \\
\hline Admixture Dosage (\%) & 1.4 & 1.2 & 1.0 \\
\hline Admixture $\left(\mathrm{kg} / \mathrm{m}^{3}\right)$ & 3.85 & 3.6 & 3.25 \\
\hline $\begin{array}{l}\text { Water Content (w.r.t WC } \\
\text { ratio) }\left(1 / \mathrm{m}^{3}\right)\end{array}$ & 137.5 & 150.0 & 156.0 \\
\hline $\begin{array}{l}\text { Water Absorption of CA } \\
@ 1.1 \%\left(1 / \mathrm{m}^{3}\right)\end{array}$ & 14.6 & 14.4 & 14.2 \\
\hline $\begin{array}{l}\text { Water Absorption of CA } \\
@ 1.3 \%\left(1 / \mathrm{m}^{3}\right)\end{array}$ & 9.3 & 9.2 & 9 \\
\hline Total Water Content $\left(1 / \mathrm{m}^{3}\right)$ & 161.4 & 173.6 & 179.2 \\
\hline
\end{tabular}

TABLE VI: FINALIZED MIX FOR M30, M35, M40, AND M45 CONCRETE

\begin{tabular}{|c|c|c|c|c|}
\hline Properties & M30 & M35 & M40 & M45 \\
\hline Mix Proportion & $1: 1.9: 3.52$ & $1: 1.72: 3.2$ & $1: 1.58: 2.93$ & $1: 1.44: 2.68$ \\
\hline $\begin{array}{l}\text { Water Cement } \\
\text { Ratio }\end{array}$ & 0.45 & 0.41 & 0.38 & 0.35 \\
\hline $\begin{array}{l}\text { Cement Content } \\
\left(\mathrm{kg} / \mathrm{m}^{3}\right)\end{array}$ & 360 & 390 & 420 & 450 \\
\hline $\begin{array}{l}\text { Sand Content } \\
\left(\mathrm{kg} / \mathrm{m}^{3}\right)\end{array}$ & 684 & 671 & 664 & 648 \\
\hline $\begin{array}{l}\text { Coarse } \\
\text { Aggregates } \\
20 \mathrm{~mm} @ 60 \% \\
\left(\mathrm{~kg} / \mathrm{m}^{3}\right)\end{array}$ & 760 & 749 & 738 & 724 \\
\hline $\begin{array}{l}\text { Coarse } \\
\text { Aggregates } \\
10 \mathrm{~mm} @ 40 \% \\
\left(\mathrm{~kg} / \mathrm{m}^{3}\right)\end{array}$ & 507 & 499 & 492 & 482 \\
\hline Admixture (\%) & 1.0 & 1.0 & 1.0 & 1.0 \\
\hline $\begin{array}{l}\text { Admixture } \\
\left(\mathrm{kg} / \mathrm{m}^{3}\right)\end{array}$ & 3.6 & 3.9 & 4.2 & 4.5 \\
\hline $\begin{array}{l}\text { Water Content } \\
\text { (w.r.t WC ratio) } \\
\left(1 / \mathrm{m}^{3}\right)\end{array}$ & 162.0 & 159.9 & 159.6 & 157.5 \\
\hline $\begin{array}{l}\text { Water } \\
\text { Absorption of } \\
\text { CA @ } 1.1 \% \\
\left(1 / \mathrm{m}^{3}\right)\end{array}$ & 13.9 & 13.7 & 13.5 & 13.3 \\
\hline $\begin{array}{l}\text { Water } \\
\text { Absorption of } \\
\text { CA @ } 1.3 \% \\
\left(1 / \mathrm{m}^{3}\right)\end{array}$ & 8.9 & 8.7 & 8.6 & 8.4 \\
\hline $\begin{array}{l}\text { Total Water } \\
\text { Content }(1 / \mathrm{m} 3)\end{array}$ & 184.8 & 182.3 & 181.7 & 179.2 \\
\hline
\end{tabular}




\section{Preparation OF SAMPles From MiX}

With the finalized design mixes, specimens were cast. For each mix, a set of six cubes were cast. Cement content for each mix was maintained as designed. During casting, tests were conducted on fresh concrete. A test for the slump of concrete was conducted immediately after mixing and discharging concrete from the mixer. Compaction factor was also conducted after the Slump test on the same mix.

Specimens were cast as specified by the standards. Each mold was filled with concrete in three layers. After pouring the first layer $5 \mathrm{~cm}$ thick, the mold was vibrated by placing it in the table vibrator. Vibrations were imparted for a short duration - just enough to make the placed concrete even and leveled. After this, the layer was scrapped using a trowel so that it can form a strong bond with the next layer. After this, the next layer was placed and the same procedure was repeated.

When the mold was filled (three layers), surplus concrete was scrapped using a trowel. The surface was then finished by rolling a tamping bar. Immediately after casting, appropriate unique identification was engraved on each specimen. The identification scheme was so selected so as not to confuse the identical specimens physically as well as in records. The specimens thus cast were stored separately under the temperature of $27 \pm 2{ }^{\circ} \mathrm{C}$ and relative humidity of $+90 \%$. Under this condition, the specimen molds were maintained for 24 hours. After this, the specimens were demolded carefully and immediately placed in the curing tank for the required curing period.

The temperature of the curing tank was maintained at $27 \pm 2$ ${ }^{\circ} \mathrm{C}$. After seven days, the specimens were removed temporarily and the water was replaced with fresh water. The water used for curing was the same as that used for mixing. Immediately after the curing period is over, the specimens were taken out from the tank, wiped dry, and taken for testing.

\section{V.RESUltS OF REBOUND HAMMER TEST}

Immediately after taking out specimens from the curing tank, they were tested for Rebound Value using Schmidt Hammer. Following operations were performed while testing for rebound value -

a) Immediately after wiping the sample dry, it was placed on the Compression Testing Machine. It was ensured that the specimen is exactly in the center with the line of action of the force of the CTM.

b) Sand After placing the specimen, it was loaded to the stress intensity of $7 \mathrm{~N} / \mathrm{sq} . \mathrm{mm}$. It was ensured that the load was applied gradually without any shock. For this, the stresscontrolled servo CTM was used, with a pacing rate of 5.2 $\mathrm{KN} / \mathrm{sec}$. Once, the desired stress intensity is reached, the load was made stable $(157.5 \mathrm{KN}$, i.e., $7 \mathrm{~N} /$ sq.mm on $150 \times 150$ mm specimen.)

c) Using the rebound hammer, the impacts were imparted to the specimen - while it was still loaded. Ten sets of impacts were imparted on each face for averaging. In the first cycle, $R$ values were observed on the front and back faces i.e., Face 1 and Face 3. After this, the load was released, and the specimen was rotated by 90 Degree along the vertical axis, thus, making Face 2 and Face 4 the front and back faces. The specimen was loaded again and the $\mathrm{R}$ values were observed for both of the faces.

d) The rebound value for the set, i.e., the absolute Rvalue is considered the average of all the readings for each set.

\section{SUMMARY OF RESULTS}

The average of Compressive Strengths of 6 samples and Rebound Value for 4 faces of 6 samples were calculated for result calculation. Based on the aforementioned tests, the following results were yielded -

TABLE VII: MEAN COMPRESSIVE STRENGTH AND R-VALUE

\begin{tabular}{lll}
\hline \hline Concrete Grade & $\begin{array}{l}\text { Compressive Strength } \\
\text { Mpa }\end{array}$ & $\begin{array}{l}\text { Absolute Average R- } \\
\text { value }\end{array}$ \\
\hline M15 & 17.8 & 18.7 \\
M20 & 21.5 & 24.5 \\
M25 & 27.8 & 28.0 \\
M30 & 31.6 & 29.5 \\
M35 & 37.9 & 32.5 \\
M40 & 42.6 & 36.0 \\
M45 & 46.9 & 39.5 \\
\hline \hline
\end{tabular}

\section{DATA ANALYSIS}

The strength and Rebound value data summarized from the detailed testing are analyzed. As a practice, rebound value as $\mathrm{X}$ data and strengths in $\mathrm{Mpa}$ as $\mathrm{Y}$ data were fed to CurveExpert - a curve-fitting software.

The software used regression analysis based on the data supplied and came up with the based fitted curves. It also gives a correlation coefficient - which for the best-fit curve shall approach 1.0. Best on the output, the best three fitted curves are selected for further analysis.

The three models which indicate the best fit is graphically shown below. The fitting was done using Here $S$ is the Strength to be estimated in Mpa and R is the rebound value a dimensionless quantity.

\section{A. The Sinusoidal Fit}

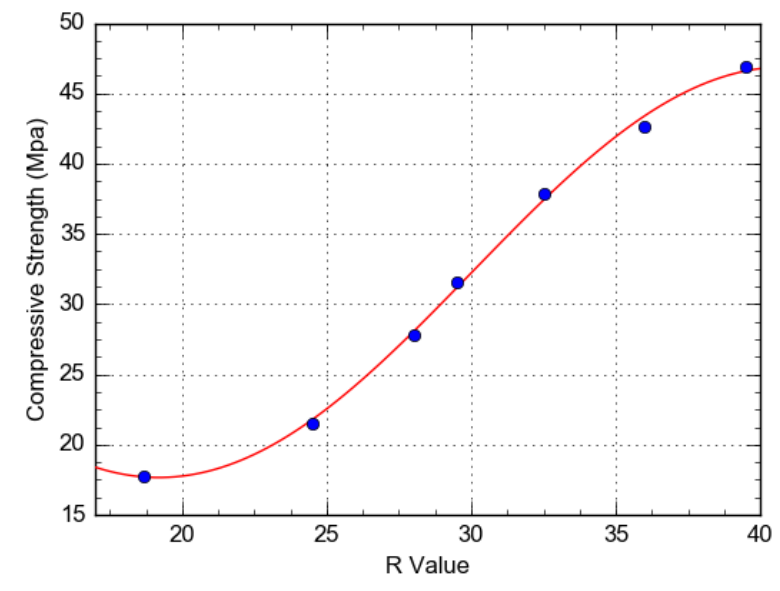

Fig. 1. Sinusoidal Fit

$S=32.27+14.6 \cos (0.145 R+0.358)$ 
In this case, the correlation coefficient is 0.99905077 . This is almost equal to 1.0 and well above the targeted value of 0.98 . Hence, upper and lower limits for this equation are not required.

\section{B. The Polynomial Fit}

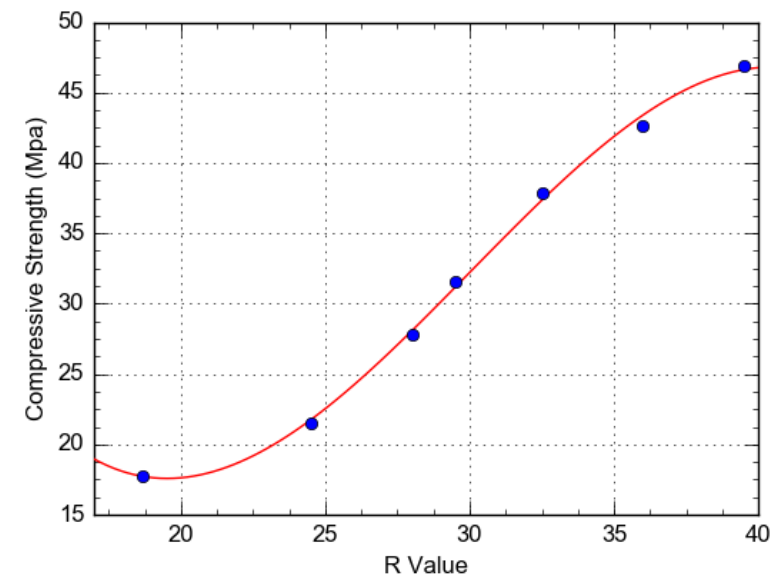

Fig. 2. Third Degree Polynomial Fit

$S=-0.0064 R^{3}+0.57 R^{2}-15.1 R+141.3$

The correlation coefficient is 0.99903763 , which is marginally lower than the Sinusoidal fit. Hence, this is ranked second.

\section{C.The Richard's Model}

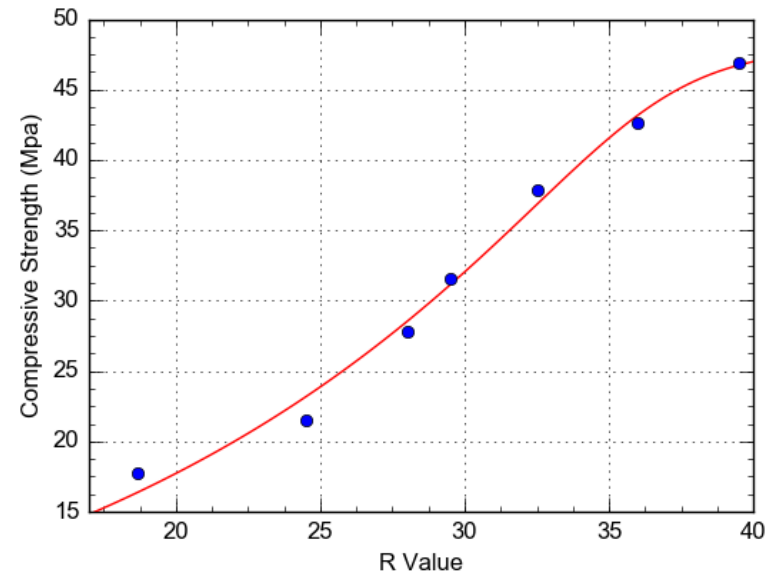

$$
S=\frac{48^{\text {Fig. 3. Richard's Model Fit }}}{\left(1+e^{18.4-0.5 R)^{\frac{1}{8.4}}}\right.}
$$

This equation is ranked third based on the correlation coefficient. However, the correlation coefficient is much lower when compared with the Sinusoidal and Polynomial fit. Hence, this equation is discarded.

\section{D.Error when using Polynomial and Sinusoidal Fit}

When the finalized two equations are used while estimating strengths, there is a small error. This is tabulated in the following table -
TABLE VIII: SINUSOIDAL FIT ERROR

\begin{tabular}{lllll}
\hline \hline R-Value & $\begin{array}{l}\text { Actual } \\
\text { Strength } \\
(\mathrm{Mpa})\end{array}$ & $\begin{array}{l}\text { Estimated Strength } \\
\text { using Sinusoidal } \\
\text { Fit (Mpa) }\end{array}$ & $\begin{array}{l}\text { Error } \\
(\mathrm{Mpa})\end{array}$ & \% Error \\
\hline 18.7 & 17.8 & 17.7 & 0.1 & 0.6 \\
24.5 & 21.5 & 21.8 & -0.3 & -1.4 \\
28.0 & 27.8 & 28.0 & -0.2 & -0.7 \\
29.5 & 31.6 & 31.1 & 0.5 & 1.6 \\
32.5 & 37.9 & 37.4 & 0.5 & 1.3 \\
36.0 & 42.6 & 43.4 & -0.8 & -1.9 \\
39.5 & 46.9 & 46.6 & 0.3 & 0.6 \\
\hline \hline
\end{tabular}

TABLE IX: THIRD-DEGREE POLYNOMIAL FIT ERROR

\begin{tabular}{lllll}
\hline \hline R-Value & $\begin{array}{l}\text { Actual } \\
\text { Strength } \\
(\mathrm{Mpa})\end{array}$ & $\begin{array}{l}\text { Estimated Strength } \\
\text { using Sinusoidal } \\
\text { Fit (Mpa) }\end{array}$ & $\begin{array}{l}\text { Error } \\
(\mathrm{Mpa})\end{array}$ & \% Error \\
\hline 18.7 & 17.8 & 17.6 & 0.2 & 1.1 \\
24.5 & 21.5 & 21.6 & -0.1 & -0.5 \\
28.0 & 27.8 & 27.9 & -0.1 & -0.4 \\
29.5 & 31.6 & 31.0 & 0.6 & 1.9 \\
32.5 & 37.9 & 37.2 & 0.7 & 1.8 \\
36.0 & 42.6 & 43.2 & -0.6 & -1.4 \\
39.5 & 46.9 & 46.4 & 0.5 & 1.1 \\
\hline \hline
\end{tabular}

With the two equations finalized, the error in estimating Strength is shown in the above tables. It can be seen that while using both the curves, the maximum error in determining the Strength is $1.9 \%$. The correlation coefficients of both equations are in close agreement. Although the Sinusoidal equation has a higher ranking, the use of third-degree polynomial fit is easier and more practicable.

Due to its simpler nature, the polynomial equation is finalized as a correlation curve.

\section{COMPARISON WITH ORIGINAL SCHMIDT CURVE}

The third-degree polynomial curve is compared with the original Schmidt rebound hammer curve. This is shown in the following graph -

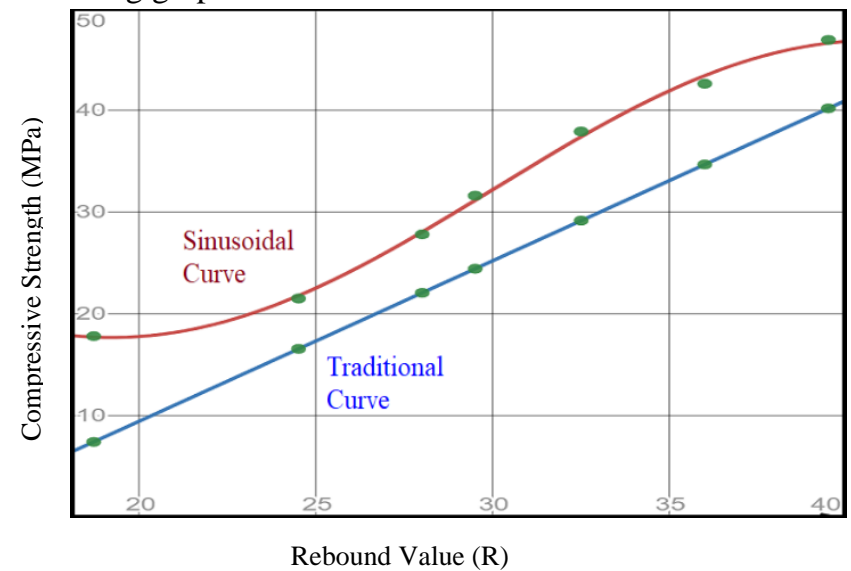

Fig. 4. Sinusoidal and Traditional Curve

From above, it can be seen that while using the traditional curve as provided with the hammer, conservative results are obtained. The new curve generated through this study gives a relatively higher value of compressive Strength for the same rebound number.

As the new curve has been generated using the local 
material, this can be used for the sites around Nagpur using the concrete in gradients available around Nagpur.

\section{Conclusion}

From the test results and data analysis, it can be concluded that, when the material used in concrete is Portland Pozzolana Cement (PPC) and locally available materials around Nagpur, the established curve gives conservative values. For local materials, a new curve as given below can be used.

$$
S=-0.0064 R^{3}+0.57 R^{2}-15.1 R+141.3
$$

This equation is valid for a strength range of 15 to $45 \mathrm{Mpa}$.

The main advantage of this curve is to have continuous quality assurance on ongoing concreting activities. Curves can be developed for early age strengths at the site itself. Once the surveys are established, there is no need to wait for compressive strength results for a period of 7 or 28 days as often done. After 3 days of casting concrete, its strength can be estimated using the on-site established curves. As such if there is any deviation in the correlation, appropriate corrective action can be taken on time.

\section{CONFLICT OF INTEREST}

The authors declare no conflict of interest.

\section{REFERENCES}

[1] Method of Test for Strength of Concrete, IS:516:1959

[2] Plain and Reinforced Concrete - Code of Practice (Fourth Revision), IS:456-2000

[3] Specifications for Coarse and Fine Aggregates from Natural Source for Concrete (Second Revision), IS:383-1970.

[4] Concrete Mix Design - Guidelines (First Revision), IS:10262-2009

[5] A M Neville \& J J Brooks, Concrete Technology, International Student Edition, Revised Reprint, Addison Wesley Longman Inc, 1997.

[6] Handbook of Concrete Mixes, SP:23-1982, Bureau Of Indian Standards.

[7] Non-Destructive Testing of Concrete-Methods of Test, Part 2 Rebound Hammer, IS:13311 Part 2-1992.

[8] Method of Making, Curing, and Determining Compressive Strength of Accelerated-Cured Concrete Test Specimens, IS:9013-1978 